\title{
Monounsaturated fats and immune function
}

P. Yaqoob

\author{
Division of Human Nutrition, School of Biological Sciences, \\ University of Southampton, Southampton, UK
}

\begin{abstract}
Correspondence
P. Yaqoob

Division of Human Nutrition

School of Biological Sciences

Biomedical Sciences Building

University of Southampton

Bassett Crescent East

Southampton SO16 7PX

UK

Fax: 441703594383

E-mail:pyaqoob@soton.ac.uk

Presented at the XII Annual Meeting of the Federação de Sociedades de Biologia Experimental, Caxambu, MG, Brasil, August 27-30, 1997.
\end{abstract}

Received August 21, 1997

Accepted September 8, 1997

\section{Abstract}

Animal studies suggest that olive oil is capable of modulating functions of cells of the immune system in a manner similar to, albeit weaker than, fish oils. There is some evidence that the effects of olive oil on immune function in animal studies are due to oleic acid rather than to trace elements or antioxidants. Importantly, several studies have demonstrated effects of oleic acid-containing diets on in vivo immune responses. In contrast, consumption of a monounsaturated fatty acid (MUFA)-rich diet by humans does not appear to bring about a general suppression of immune cell functions. The effects of this diet in humans are limited to decreasing aspects of adhesion of peripheral blood mononuclear cells, although there are trends towards decreases in natural killer cell activity and proliferation. The lack of a clear effect of MUFA in humans may be attributable to the higher level of monounsaturated fat used in the animal studies, although it is ultimately of importance to examine the effects of intakes which are in no way extreme. The effects of MUFA on adhesion molecules are potentially important, since these molecules appear to have a role in the pathology of a number of diseases involving the immune system. This area clearly deserves further exploration.

\section{Introduction}

The Mediterranean diet has become a cultural model for dietary improvement. Since the 1950s there has been growing evidence that Mediterranean countries display rates of chronic diseases that are amongst the lowest in the world and life expectancies that are amongst the highest (1). The Mediterranean diet is characterised by the use of olive oil as the major culinary fat and, although the total intake of fat may be relatively high, this is strongly correlated with a low intake of saturated fat (2). As the Seven Countries Study (2) clearly showed, it is the type of fat rather than the level of fat consumed in the diet that is most closely related to the inci-

\section{Key words}

- Fatty acids

- Lipids

- Immunity

- Olive oil

- Adhesion molecules dence of coronary heart disease and subsequent studies have shown that the replacement of saturated fatty acids (SFA) with either monounsaturated fatty acids (MUFA) or polyunsaturated fatty acids (PUFA) may be beneficial $(3,4)$.

Since the consumption of diets rich in MUFA has been linked with a low prevalence of atherosclerosis, there has been great interest in the effects of MUFA on lipoprotein metabolism (4). Less attention has been paid to the effects of MUFA on the immune system, although cells of the immune system are an inherent part of the inflammatory events which are involved in the development and progression of atherosclerosis.

Olive oil has classically been used as a 
placebo treatment in studies investigating the effects of fish oils on immune function and in various human disease conditions, since MUFA have typically been regarded as being neutral $(5,6)$. However, a number of clinical trials have reported effects of the olive oil treatment which are equal or similar to the effects of the treatment under test (usually fish oil). One such study reported no significant difference between fish oil supplements and an olive oil placebo in preventing restenosis after coronary angioplasty (7); a subsequent letter to The Lancet suggests that "...future studies of oil supplements should not consider olive oil as a placebo until there are more data evaluating the role of MUFA ..." (8).

A smaller number of studies have suggested that there may be beneficial effects of olive oil consumption on rheumatoid arthritis (9), an autoimmune disease characterised by infiltration of synovial tissues and fluid by cells of the immune system and vigorous overactivity and inflammation therein. In particular, a much-cited study by Linos et al. (10) shows that frequent consumption of olive oil decreases the relative risk for developing rheumatoid arthritis. It is proposed that the suppressive effect of olive oil on the development of rheumatoid arthritis may be exerted via an effect on the immune system.

Studies investigating the effects of

Figure 1 - Effect of dietary lipid manipulation on proliferation of rat mesenteric lymph node lymphocytes cultured in autologous serum or foetal calf serum (FCS). Rats were fed for 10 weeks on either a low-fat diet (LF) or diets containing $200 \mathrm{~g} / \mathrm{kg}$ coconut oil (CO), olive oil (OO), safflower oil (SO), evening primrose oil (EPO) or fish oil (FO). Proliferation in response to $5 \mu \mathrm{g} / \mathrm{ml}$ Con A was measured by incorporation of $\left[{ }^{3} \mathrm{H}\right]$ thymidine. ${ }^{*} \mathrm{P}<0.05 \mathrm{com}$ pared to the low-fat diet (oneway analysis of variance). Data taken from Yaqoob et al. (13), with permission of Blackwell Science Ltd. flower oils) or $n$-3 PUFA (such as linseed or fish oils). In general, the $n-6$ PUFA are believed to enhance immune function and the $n$-3 PUFA to suppress it (11). However, there is now growing evidence that MUFArich oils, which were previously thought to be neutral with respect to immune function, have effects which are similar to fish oils. The purpose of this review is to discuss and evaluate the evidence that monounsaturated fats can influence the composition and functions of cells of the immune system.

\section{Effects of olive oil on ex vivo lymphocyte proliferation}

The in vitro effects of fatty acids on lymphocyte proliferation have been studied since the early 1970s and have been reviewed in detail elsewhere $(11,12)$. These studies have investigated the effects of a large range of fatty acids, including oleic acid, the major fatty acid contained in olive oil, but the results are disparate and comparisons between studies are made difficult by the differences in the concentrations of fatty acids used, the cell type studied, the means by which they were presented to cells and the conditions of incubation. The in vitro studies therefore remain contradictory, some showing no effect of oleic acid and some showing a suppression of lymphocyte proliferation $(11,12)$.

In order to obtain information about the effects of dietary lipids, we have investigated the effects of feeding rats a range of high-fat $(200 \mathrm{~g} / \mathrm{kg})$ diets, each with a characteristic fatty acid composition, or a low-fat ( $25 \mathrm{~g} / \mathrm{kg}$ corn oil) diet on lymphocyte fatty acid composition and on a number of lymphocyte functions. In these studies, the animals were fed on hydrogenated coconut oil, olive oil, safflower oil, evening primrose oil or fish (menhaden) oil for a period of 10 weeks. The first of these studies reported a significant suppressive effect of olive oil on the ex vivo proliferation of mesenteric lymph 
node lymphocytes in response to the T-cell mitogen, concanavalin A (Con A), when compared with feeding a low-fat diet or diets rich in hydrogenated coconut oil or safflower oil (13; Figure 1). The effect of the olive oil diet was similar in magnitude to those of the fish oil or evening primrose oil diets (13; Figure 1) and was also demonstrated in whole blood cultures stimulated with sub-optimal concentrations of Con A (14; Figure 2). All of the high-fat diets were shown to modulate the fatty acid composition of lymphocytes, resulting in characteristic profiles for each dietary group (15). Only one other study has examined the effects of feeding an olive oilrich diet on lymphocyte proliferation in rodents. The study of Berger et al. (16) compared the effects of feeding a low-fat $(30 \mathrm{~g} /$ $\mathrm{kg}$ ), olive oil (100 g/kg), safflower oil (100 g/ $\mathrm{kg})$, linseed oil $(100 \mathrm{~g} / \mathrm{kg})$ or fish plus safflower oil $(90+10 \mathrm{~g} / \mathrm{kg})$ diet to dams for 5 months on the proliferation of Con A-stimulated murine spleen lymphocytes of their pups prior to weaning. In contrast to the studies described above, they found no effect of dietary manipulation (16). There are several possible reasons for this. First, the high-fat diets used by Berger et al. (16) contained half the total amount of fat used in our studies. Second, Berger et al. fed murine dams on each of the diets and then tested lymphocyte proliferation using cells from the pups before weaning, whereas our studies used rats fed for 10 weeks immediately after weaning. It is possible that in the study of Berger et al. the suckling pups may not have been exposed to milk of sufficiently differing fatty acid composition to allow dietary lipid manipulation to occur through this transition. Third, in the study by Berger et al., lymphocytes were cultured in foetal calf serum, whereas in our studies cells were cultured in autologous serum or as whole blood cultures; we have shown that culturing cells for $48 \mathrm{~h}$ in foetal calf serum, but not autologous serum, reverses the changes in fatty acid composition brought about by di- etary lipid manipulation (15) and masks any effects of dietary lipid manipulation on cell function (13; Figure 1).

Since olive oil contains a number of antioxidants, sterols, hydrocarbons and alcohols (17), it seemed important to determine whether the effects observed following feeding of this diet to rats were due to oleic acid or to some other component of the oil. This was investigated using a diet rich in higholeic acid sunflower oil (18); in earlier studies, feeding the safflower oil diet had no effect on proliferation of lymph node lymphocytes (13; Figure 1) or of whole blood cultures (14; Figure 2). The effects of feeding a diet containing high-oleic acid sunflower oil were therefore compared with the effects of feeding the low-fat, olive oil or safflower oil diet (18). The fatty acid composition of spleen lymphocyte lipids was strongly affected by that of the diets fed; importantly, the high-oleic acid sunflower oil and olive oil diets resulted in a significantly higher proportion of oleic acid in

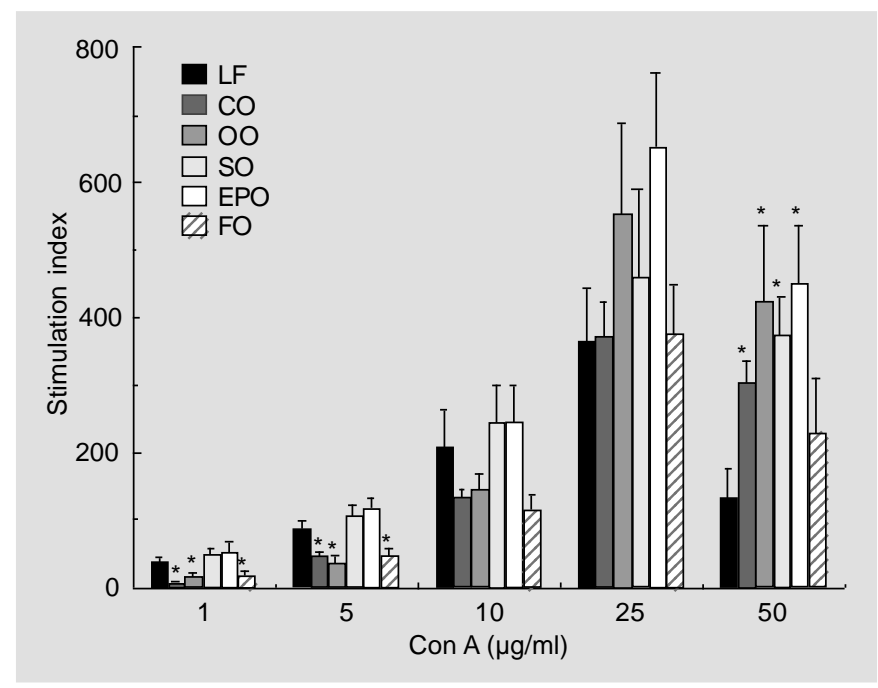

Figure 2 - The effect of dietary lipid manipulation on the proliferation of Con A-stimulated whole blood cultures. Rats were fed for 10 weeks on either a low-fat diet (LF) or diets containing $200 \mathrm{~g} / \mathrm{kg}$ coconut oil (CO), olive oil (OO), safflower oil (SO), evening primrose oil (EPO) or fish oil (FO). Proliferation of whole blood (heparinised blood diluted 1:10 with culture medium containing RPMI, $2 \mathrm{mM}$ glutamine and antibiotics) in response to Con $\mathrm{A}$ was measured by incorporation of $\left[{ }^{3} \mathrm{H}\right]$ thymidine. ${ }^{*} \mathrm{P}<0.05 \mathrm{com}$ pared to the low-fat diet (one-way analysis of variance). Data taken from Yaqoob et al. (14), with permission of Elsevier Science Inc. 
Figure 3 - The effect of feeding a high-oleic acid sunflower oil diet on proliferation of rat spleen lymphocytes. Lymphocytes were cultured in autologous serum in the absence or presence of Con $A$; lymphocyte proliferation is expressed as stimulation index. Statistical significance is indicated as: ${ }^{\mathrm{a}}$ vs low-fat (LF); ${ }^{\mathrm{b}}$ vs olive oil (OO); ${ }^{c} v s$ safflower oil (SO); ${ }^{d} v s$ high-oleic acid sunflower oil (HOSO). Data taken from Jeffery et al. (18), with permission of S. Karger AG, Basel.

Figure 4 - Relationship between the oleic acid:linoleic acid (OA:LA) ratio in the diet and spleen lymphocyte proliferation in rats. Data taken from Jeffery et al. (19), with permission of the Nutrition Society.

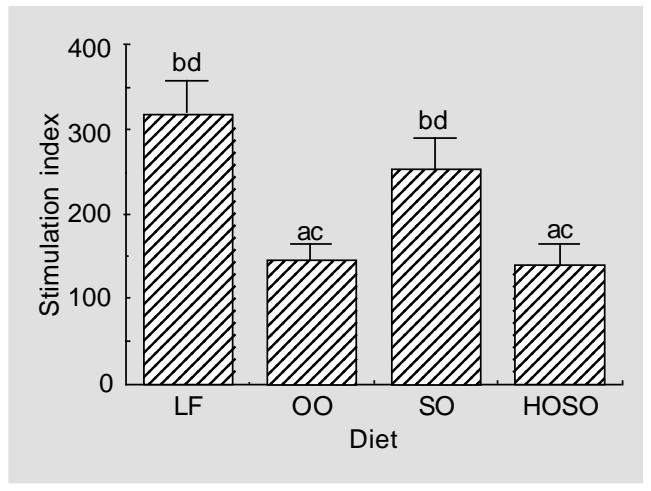

lymphocyte lipids than the low-fat or safflower oil diet (18). Feeding either the olive oil or the high-oleic acid sunflower oil diet significantly decreased the proliferation of spleen lymphocytes compared with feeding the low-fat or safflower oil diet; the effects of the olive oil and high-oleic acid sunflower oil diets were not significantly different from one another (18; Figure 3). This suggests that the effects of the olive oil diet are likely to be due to oleic acid rather than to other components of olive oil.

The studies outlined above have used relatively large amounts of a single oil and as such they represent very extreme diets, which are unlikely to be encountered by free-living human beings. Furthermore, the use of such oils inevitably results in variation in the levels of several fatty acids together and not only of the one under investigation. A further study therefore investigated the effects of relatively small changes in the levels of commonly consumed fatty acids in a controlled manner in which one fatty acid was exchanged for another, without altering the

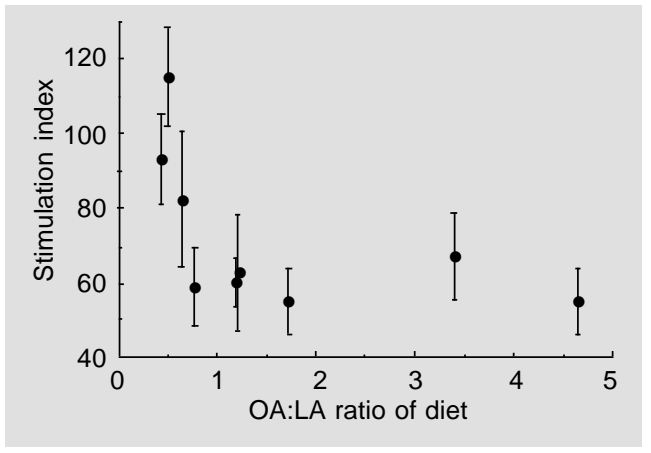

Table 1 - Fatty acid composition of diets used in the study of Jeffery et al. (19).

Fatty acid (g/100 g total fatty acids)

\begin{tabular}{lrrrr}
\cline { 2 - 5 } Diet & $16: 0$ & $18: 1 n-9$ & $18: 2 n-6$ & $18: 3 n-3$ \\
\hline A & 56.6 & 18.5 & 15.4 & 2.1 \\
B & 37.9 & 19.8 & 30.9 & 4.4 \\
C & 21.9 & 19.7 & 45.8 & 6.3 \\
D & 10.3 & 25.2 & 51.7 & 6.8 \\
E & 6.2 & 35.6 & 46.2 & 6.6 \\
F & 22.4 & 36.8 & 30.3 & 4.2 \\
G & 22.4 & 53.1 & 15.6 & 2.2 \\
H & 5.2 & 53.7 & 30.9 & 4.4 \\
I & 4.5 & 71.6 & 15.4 & 2.2
\end{tabular}

levels of other fatty acids in the diet (19). The nine diets used in this study contained $178 \mathrm{~g} / \mathrm{kg}$ fat, and differed in their proportions of palmitic, oleic, linoleic and $\alpha$-linolenic acids whilst maintaining a constant $n-6$ PUFA: $n$-3 PUFA ratio of 7 (Table 1). The effect on lymphocyte proliferation of replacing one fatty acid with another appeared to be influenced by the level of other fatty acids in the diet. On further examination, there was a significant inverse linear relationship between proliferation (reported as stimulation index) and the oleic acid:linoleic acid ratio of the diet $(r=0.331 ; \mathrm{P}=0.028)$. However, the best-fit relationship was of the form:

stimulation index $=$

$$
\mathrm{a}_{0}+\mathrm{b}_{0} \log \text { (oleic acid:linoleic acid) }
$$

where $\mathrm{a}_{0}=75.8$ and $\mathrm{b}_{0}=-18.56(\mathrm{P}<0.05$ for both values). This relationship is illustrated in Figure 4; the authors showed that lymphocyte proliferation is decreased with increasing dietary oleic acid levels up to an oleic acid level of $35.6 \mathrm{~g} / 100 \mathrm{~g}$ fatty acids (diet E), but increasing the oleic acid level above this value does not result in any further increase (19).

Studies carried out in our laboratory have recently been extended to human work; we have performed a study to investigate the effects of consumption of a MUFA-rich diet for 2 months on immune function in healthy 
middle-aged men. Middle-aged men (mean age 48 years; range $41-56$ years; BMI range $21.9-30.7 \mathrm{~kg} / \mathrm{m}^{2}$ ) were randomly assigned to consume either a control diet (designed to reproduce the current UK diet fatty acid composition) or a diet containing foods enriched with highly refined olive oil for 8 weeks. Foods provided for subjects included the main meal of the day (as a frozen recipe meal), cooking oils and spreads, biscuits and puddings. Subjects on the MUFA diet consumed significantly less saturated fat (\% energy) compared with those on the control diet and significantly more MUFA; MUFA contributed $18.4 \%$ energy in this group compared with $11.3 \%$ in the control group. Consumption of a MUFA-rich diet did not affect the proliferative response of either whole blood cultures (Figure 5) or peripheral blood mononuclear cells (PBMNC; Figure 6) to the T-cell mitogen, concanavalin A (20). This observation contrasts with results obtained using laboratory animals (20). The lack of a clear effect of MUFA may be attributable to the higher level of monounsaturated fat used in the animal studies; in these studies rats were fed for 10 weeks on diets containing $200 \mathrm{~g} / \mathrm{kg}$ olive oil (MUFA therefore contributed approximately $30 \%$ of total energy intake), whereas in the human study, MUFA contributed approximately $18 \%$ of the total energy intake. While it is possible that a higher level of dietary MUFA may have resulted in suppression of proliferation, the purpose of the study was to examine the effects of intakes which are in no way extreme; the intakes employed in the human study closely correspond to current Mediterranean intakes (21) and can readily be achieved through consumption of meals which use olive oil as the primary cooking fat.

\section{Effects of olive oil on ex vivonatural killer cell activity}

One of the most important mechanisms
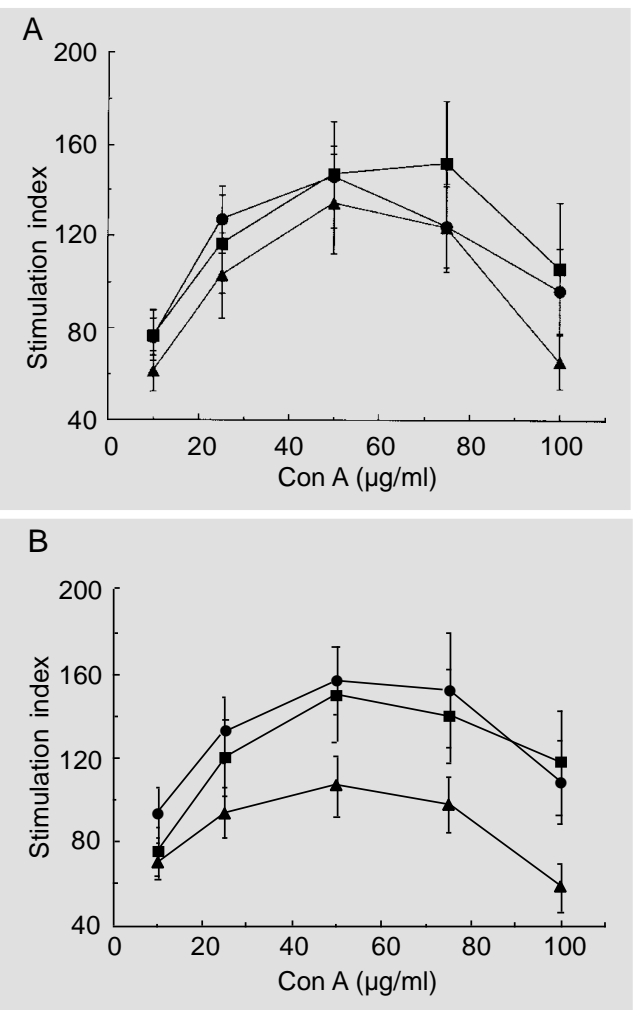

by which the immune system deals with foreign cells is to damage or destroy them. Typical target cells include malignant cells, normal cells of the host that are infected with viruses or other microorganisms and normal cells from individuals unrelated to the responding host. Natural killer (NK) cells are a subset of lymphocytes found mainly in blood and the spleen (22). They are derived from the bone marrow, but are neither $\mathrm{T}$ cells nor $B$ cells and they do not undergo thymic maturation. Killing by NK cells is part of natural rather than specific immunity, since it is not induced by a specific antigen and is

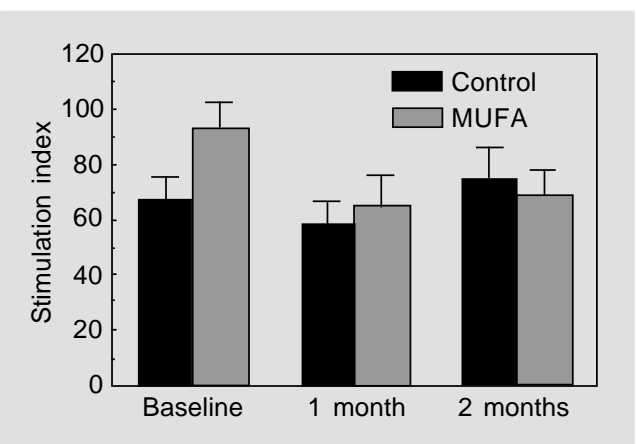

Figure 5 - Effect of MUFA consumption on proliferation of leukocytes in whole blood in healthy middle-aged men. $A$, Control group; $B$, MUFA group. (squares, baseline; circles, 1 month; triangles, 2 months). Proliferation, measured as thymidine incorporation, is expressed as stimulation index. Data are reported as mean \pm SEM of 22 29 subjects in each group. There were no significant effects of the MUFA diet as analysed by two-way repeat-measures ANOVA. Data taken from Yaqoob et al. (20), with permission.

Figure 6 - Effect of MUFA consumption on proliferation of PBMNC in healthy middle-aged men. Proliferation, in response to $15 \mu \mathrm{g} / \mathrm{ml}$ concanavalin $\mathrm{A}$, was assessed as $\left[{ }^{3} \mathrm{H}\right]$ thymidine incorporation and is expressed as stimulation index. Data are reported as mean \pm SEM of 21-29 subjects in each group. Significant effects of time and diet and their interactions were analysed by two-way repeat-measures ANOVA (no significant differences found). Data taken from Yaqoob et al. (20), with permission. 
Table 2 - The effect of dietary lipid manipulation on natural killer cell activity in freshly prepared rat spleen lymphocytes.

Cytolysis of YAC-1 (target) cells by rat spleen lymphocytes (effector cells) was measured by release of ${ }^{51} \mathrm{Cr}$ by pre-loaded YAC-1 cells at various ratios of effector:target cells $(100: 1,50: 1,25: 1,12.5: 1)$. Results are reported as \% cytolysis. Statistical significance for $\mathrm{P}<0.05$ is indicated as follows: ${ }^{a} v s$ low-fat (LF); ${ }^{b}$ ss hydrogenated coconut oil (HCO); ${ }^{c} v s$ olive oil (OO); ${ }^{d} v s$ safflower oil (SO); ${ }^{\mathrm{e}} v s$ evening primrose oil (EPO); ${ }^{\mathrm{f}} v s$ fish oil (FO). Data taken from Yaqoob et al. (23), with permission of Elsevier Science.

\begin{tabular}{|c|c|c|c|c|}
\hline \multirow[t]{2}{*}{ Diet } & \multicolumn{4}{|c|}{ \% Cytolysis } \\
\hline & $100: 1$ & $50: 1$ & $25: 1$ & $12.5: 1$ \\
\hline LF & $46.5 \pm 2.0^{\text {cef }}$ & $29.7 \pm 2.8^{\text {cef }}$ & $17.7 \pm 2.1^{\text {bcdef }}$ & $7.4 \pm 1.2^{\mathrm{cef}}$ \\
\hline $\mathrm{HCO}$ & $40.4 \pm 2.4^{f}$ & $22.9 \pm 1.5^{f}$ & $11.5 \pm 0.6^{\text {afe }}$ & $4.5 \pm 0.8$ \\
\hline O० & $36.4 \pm 2.8^{a}$ & $20.8 \pm 1.7$ af & $9.3 \pm 0.9^{a f}$ & $3.4 \pm 0.4^{a}$ \\
\hline so & $42.1 \pm 1.5^{f}$ & $24.2 \pm 1.3^{f}$ & $11.2 \pm 1.1^{\text {af }}$ & $3.9 \pm 0.7$ \\
\hline EPO & $40.7 \pm 0.7^{\text {af }}$ & $19.1 \pm 2.6^{a}$ & $8.9 \pm 0.2^{\mathrm{abf}}$ & $3.2 \pm 0.4^{a}$ \\
\hline FO & $29.4 \pm 2.1$ abde & $13.6 \pm 0.7 \mathrm{abcd}$ & $5.0 \pm 0.3^{\mathrm{abcde}}$ & $3.1 \pm 0.8^{a}$ \\
\hline
\end{tabular}

Figure 7 - The effect of feeding a high-oleic acid sunflower oil diet on rat spleen lymphocyte natural killer cell activity. Cytolysis of YAC-1 (target) cells by rat spleen lymphocytes (effector cells) was measured by release of ${ }^{51} \mathrm{Cr}$ by pre-loaded YAC-1 cells at a ratio of 100:1 effector:target cells. Results are expressed as \% cytolysis. Statistical significance is indicated as: ${ }^{a}$ vs low-fat (LF); ${ }^{\text {b } v s}$ olive oil (OO); ${ }^{c} v s$ safflower oil (SO); dvs high-oleic acid sunflower oil (HOSO). Data taken from Jeffery et al. (18), with permission of S. Karger AG, Basel.

Figure 8 - Relationship between the oleic acid content of the diet and spleen natural killer (NK) cell activity in rats. From Jeffery et al. (19), with permission of the Nutrition Society.

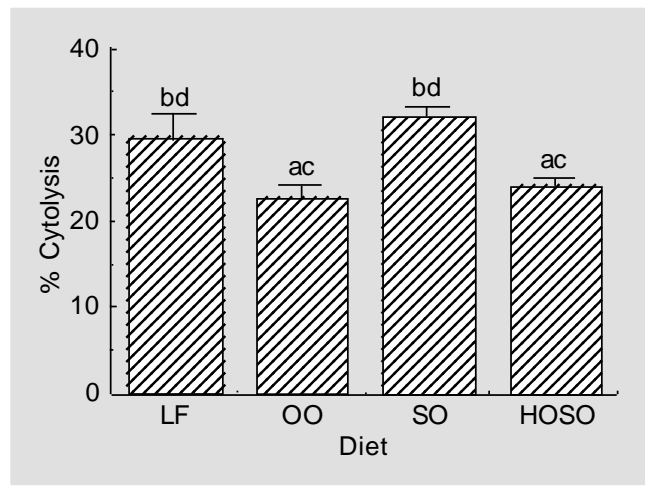

not restricted by MHC molecules.

Feeding rats for 10 weeks on a diet containing $200 \mathrm{~g} / \mathrm{kg}$ olive oil results in significant suppression of NK cell activity compared with feeding a low-fat diet or diets containing $200 \mathrm{~g} / \mathrm{kg}$ hydrogenated coconut oil or safflower oil (23; Table 2). The inhibition of NK cell activity is greater than that produced by feeding a diet rich in evening primrose oil (23; Table 2), but not as great as that resulting from feeding a diet containing $200 \mathrm{~g} / \mathrm{kg}$ fish oil (23; Table 2). As with the experiments on lymphocyte proliferation described above, when the effects of high-oleic acid sunflower oil were compared with those of olive oil, NK cell activity was significantly lower for spleen lymphocytes from rats fed the olive oil or the high-oleic acid sunflower oil than for those from rats fed the low-fat or the safflower oil diets (18; Figure 7 ); the effects of the olive and high-oleic acid sunflower oils were not significantly different from one another (18; Figure 7). Once again, this suggests that the effects of the olive oil diet are likely to be due to oleic acid rather than to other components of olive oil.

In a study comparing the effects of diets A-I (Table 1) on NK cell activity, there was a significant negative linear relationship between the oleic acid content of the diet and NK cell activity, suggesting that dietary oleic acid causes diminished NK cell activity (19; Figure 8). Furthermore, there was a negative relationship between the oleic acid:linoleic acid ratio in the diet and NK cell activity and a weak negative relationship $(r=-0.289 ; \mathrm{P}=$ 0.092 ) between NK cell activity and the level of oleic acid in spleen lymphocytes (19).

The study by Berger et al. (16) also examined the effects of a range of high-fat diets on NK cell activity. This study showed no effect of an olive oil-rich diet on NK cell activity in mice when compared with a lowfat, safflower oil or linseed oil diet (16); once again, the reasons for the lack of effect may be attributable to the amount of fat in 


\begin{tabular}{|c|c|c|c|c|c|c|}
\hline \multirow[b]{3}{*}{$\mathrm{E} / \mathrm{T}$ ratio } & \multicolumn{6}{|c|}{$\%$ Cytolysis } \\
\hline & \multicolumn{2}{|c|}{ Baseline } & \multicolumn{2}{|c|}{1 month } & \multicolumn{2}{|c|}{2 months } \\
\hline & $\begin{array}{l}\text { Control } \\
N=19\end{array}$ & $\begin{array}{l}\text { MUFA } \\
N=21\end{array}$ & $\begin{array}{l}\text { Control } \\
N=25\end{array}$ & $\begin{array}{l}\text { MUFA } \\
N=24\end{array}$ & $\begin{array}{l}\text { Control } \\
N=15\end{array}$ & $\begin{array}{l}\text { MUFA } \\
\mathrm{N}=19\end{array}$ \\
\hline $100: 1$ & $60.9 \pm 4.2$ & $58.8 \pm 4.6$ & $63.7 \pm 3.2$ & $58.7 \pm 4.0$ & $63.0 \pm 9.3$ & $52.4 \pm 4.5$ \\
\hline $50: 1$ & $41.5 \pm 3.6$ & $40.7 \pm 3.3$ & $43.3 \pm 3.1$ & $36.9 \pm 3.9$ & $43.2 \pm 4.9$ & $34.2 \pm 3.4$ \\
\hline $25: 1$ & $28.6 \pm 3.4$ & $25.1 \pm 2.8$ & $28.0 \pm 2.4$ & $24.2 \pm 2.8$ & $25.4 \pm 2.9$ & $23.5 \pm 3.3$ \\
\hline $12.5: 1$ & $18.8 \pm 2.5$ & $15.2 \pm 2.0$ & $18.5 \pm 1.7$ & $14.3 \pm 1.8$ & $16.0 \pm 2.2$ & $13.4 \pm 2.4$ \\
\hline
\end{tabular}

the diet and/or the protocol used (dams fed for 5 months and pups subsequently used prior to weaning).

In a study investigating the effects of MUFA on immune function in healthy, middle-aged men (20), consumption of the MUFA diet produced a small decrease in NK cell activity at 2 months, but not at 1 month (20; Table 3). However, this was not statistically significant when compared either with the baseline or with the control group, largely due to the small sample size for the control group at 2 months (20; Table 3 ). Natural killer cell activity was unaffected by consumption of the control diet (20; Table $3)$. As was seen with the effects of olive oil on lymphocyte proliferation, this observation contrasts with animal studies, which have shown a strong suppression of NK cell activity by an olive oil-rich diet (23) and may be attributable to the higher level of monounsaturated fat used in the animal studies. It is interesting to note, however, that the small changes in NK cell activity and proliferation observed after 2 months of consumption of the MUFA diet were accompanied by a small, but significant increase in the proportion of oleic acid in plasma phospholipids (20) and in PBMNC (20).

\section{Effects of olive oil on expression of adhesion molecules}

Recent advances in our understanding of basic mechanisms of inflammation, of cellcell interactions and of leukocyte trafficking have highlighted the importance of adhesive interactions between leukocytes and cellular or extracellular components of tissues. There has been a significant expansion of knowledge regarding the role of cell surface adhesion molecules in these processes over the last 10 years and a number of adhesion molecules have been classified into families according to sequence homology and functions. It has been suggested that some adhesion molecules may have pathophysiological as well as physiological roles; some adhesion molecules have been implicated in the transendothelial migration of leukocytes into synovial tissue and fluid in rheumatoid arthritis (24) and in leukocyte-endothelium interactions which lead to the formation of atherosclerotic plaques (24). There has consequently been a great deal of interest in recent years in the potential modulation of the expression and/or functions of adhesion molecules by fatty acids, particularly those of the $n-3$ PUFA family. Once again, the 
Figure 9 - Effect of preincubation $(24 \mathrm{~h})$ with fatty acids on surface expression of VCAM-1 by HSVEC in response to stimulation $(6 \mathrm{~h})$ with TNF $\alpha$. VCAM-1 expression is measured in $\mathrm{mU}$ of absorbance by a cell surface enzyme immunoassay. Expression of VCAM- 1 by cells preincubated with oleic acid was significantly lower than in control or AA-treated cells and expression of VCAM- 1 by cells preincubated with DHA was significantly lower than that of all other groups, apart from OA-treated cells. OA, Oleic acid; AA, arachidonic acid; EPA, eicosapentaenoic acid; DHA, docosahexaenoic acid. Data taken from De Caterina et al. (25), with permission of the American Heart Association.

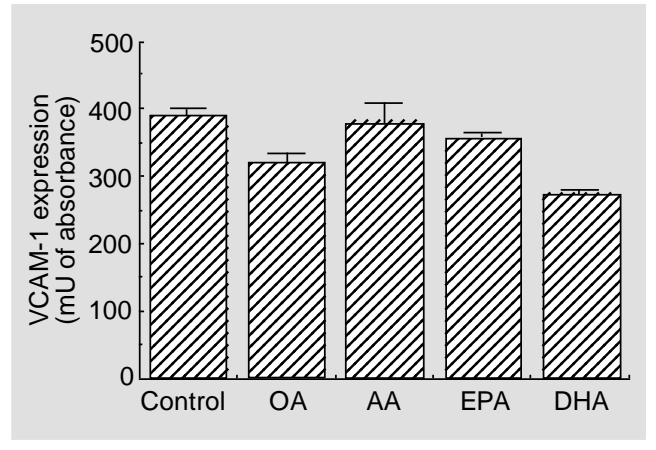

intense interest in fish oils and $n-3$ PUFA has overshadowed some potentially exciting effects of MUFA on adhesion molecule expression.

In a study by De Caterina et al. (25), human saphenous vein endothelial cells (HSVEC) were preincubated for $24 \mathrm{~h}$ with $10 \mu \mathrm{M}$ arachidonic acid (AA), docosahexaenoic acid (DHA), eicosapentaenoic acid (EPA) or oleic acid prior to $6 \mathrm{~h}$ of stimulation with tumour necrosis factor- $\alpha(\mathrm{TNF} \alpha)$ and subsequent measurement of the surface expression of vascular cell adhesion molecule1 (VCAM-1). It was reported that DHA (but not EPA) and oleic acid significantly decreased the expression of VCAM-1 by HSVEC (25; Figure 9). The authors concluded that since DHA produced the greatest inhibition, further experiments in the study would focus exclusively on this fatty acid. They went on to report time- and concentra- tion-dependent inhibition of the expression of E-selectin and intercellular adhesion molecule-1 (ICAM-1) by DHA, a reduction in the accumulation of VCAM-1 mRNA and an inhibition of the adhesion of human monocytic cells (U937) to DHA-treated HSVEC (25). Since oleic acid had the same effect on VCAM-1 expression as DHA in the initial experiment (25; Figure 9), it is unfortunate that the remainder of the study focussed solely on DHA.

In a dietary study comparing the effects of low-fat $(25 \mathrm{~g} / \mathrm{kg})$ and high-fat diets containing $200 \mathrm{~g} / \mathrm{kg}$ hydrogenated coconut oil, olive oil, safflower oil, evening primrose oil or fish oil, the level of expression of the adhesion molecules CD2, ICAM-1 and LFA1 on rat spleen lymphocytes was decreased by both olive oil and fish oil (26). In the human study carried out by our group (20), a MUFA-rich diet resulted in a significant decrease in the expression of the leukocyte adhesion molecule, ICAM-1, after 2 months of consuming the diet compared both with baseline values and with those from the control group (20; Table 4). The expression of ICAM- 1 did not change during the consumption of the control diet (20; Table 4). The MUFA diet also decreased the expression of a monocyte/macrophage-associated adhesion molecule, Mac-1, by approximately $25 \%$

Table 4 - Effect of MUFA consumption on expression of surface molecules on PBMNC in healthy middle-aged men.

Data are reported as mean \pm SEM of the indicated number of analyses. ' $n s$ ' indicates no significant effect of time or diet or interaction between time and diet as analysed by two-way repeat-measures ANOVA. ' $a$ ' denotes a significant effect of diet $(P=0.035)$ and time $(P=0.049)$, with a significant interaction $(P=0.046)$. Significant differences between groups (Student $t$-test) are indicated as follows: ${ }^{*} \mathrm{P}<0.05$ vs control group; $+P<0.01$ vs baseline. Data taken from Yaqoob et al. (20), with permission.

\begin{tabular}{|c|c|c|c|c|c|c|c|}
\hline \multicolumn{8}{|c|}{$\%$ Marker-positive cells } \\
\hline & \multicolumn{2}{|c|}{ Baseline } & \multicolumn{2}{|c|}{1 month } & \multicolumn{2}{|c|}{2 months } & \multirow[b]{2}{*}{ ANOVA } \\
\hline & $\begin{array}{c}\text { Control } \\
N=18-20\end{array}$ & $\begin{array}{c}\text { MUFA } \\
N=19-20\end{array}$ & $\begin{array}{l}\text { Control } \\
N=18-23\end{array}$ & $\begin{array}{c}\text { MUFA } \\
N=20-23\end{array}$ & $\begin{array}{c}\text { Control } \\
N=20-23\end{array}$ & $\begin{array}{c}\text { MUFA } \\
N=19-21\end{array}$ & \\
\hline CD54 & $19.0 \pm 1.3$ & $20.8 \pm 1.4$ & $19.1 \pm 1.2$ & $16.4 \pm 1.4$ & $20.0 \pm 1.5$ & $15.9 \pm 1.1^{*+}$ & a \\
\hline CD11b & $15.5 \pm 1.2$ & $17.0 \pm 1.8$ & $15.4 \pm 1.4$ & $15.4 \pm 1.3$ & $13.7 \pm 1.3$ & $12.6 \pm 1.5$ & ns \\
\hline
\end{tabular}


compared with baseline values. However, this decrease was not statistically significant, either compared with the baseline or with the control group (20; Table 4). The decrease in the expression of ICAM-1 by the MUFA diet is an important finding. ICAM-1 is a member of the Ig superfamily of adhesion molecules and is involved in leukocyteleukocyte adhesion (27) as well as adhesion of leukocytes to endothelial cells (24) and to fibrinogen, a plasma adhesive protein (28). ICAM-1 is expressed on mononuclear cells that infiltrate inflamed synovium in patients suffering from rheumatoid arthritis (29) and in some cases, such patients may also have high levels of serum soluble ICAM-1 (29). The formation of plaques in atherosclerosis shows many features which are common to the inflammation seen in rheumatoid arthritis, such as adhesive interactions between endothelial cells and leukocytes and extravascular leukocyte accumulation and ICAM-1 is thought to play a pivotal role in the recruitment of mononuclear cells to, and therefore the growth of, the atherosclerotic plaque (30).

Recent evidence suggests that a MUFArich diet may indeed affect the process of cellular adhesion. In an interesting study by Mata et al. (31), healthy men and women living in a religious community were subjected to four consecutive dietary periods (isocaloric) differing in the fat content of SFA, MUFA and $n-3$ and $n-6$ PUFA. It was reported that LDL-induced monocyte adhesion to endothelial cells was lower during the MUFA period than each of the others and that resistance of LDL to oxidation was greatest during the MUFA period (31). The authors suggest that the modulation of LDL fatty acid composition was responsible for the differences in adhesion and showed a significant negative correlation between monocyte adhesion to endothelial cells and the oleic acid content of LDL (31). Expression of adhesion molecules by either cell type was not measured, but it is possible that this too may have played some role in the decreased adhesion during the MUFA period.

The fact that a high MUFA diet appears to decrease the expression of ICAM-1 on circulating PBMNC by up to $20 \%$ opens up the exciting possibility that the low prevalence of atherosclerosis, and perhaps other inflammatory conditions, in Mediterranean populations may at least partly involve the effects of dietary MUFA on adhesion molecule expression; this is a potentially important area which clearly deserves further exploration.

\section{Effects of olive oil on in vivo immuneresponses}

The ex vivo studies described so far, whilst limited in number, build an interesting picture of the possible influences of olive oil on immune function. However, once observations have been made ex vivo, it is important to extend these to in vivo studies. Mulrooney and Grimble (32) have achieved this by investigating the inflammatory response to $\mathrm{TNF} \alpha$ in rats. This situation mimics the invasion of the body by infective and inflammatory agents, which would result in the release of cytokines from cells of the immune system. The purpose of the released cytokines, apart from modulation of the immune system, is to bring about enhanced lipolysis, gluconeogenesis, muscle proteolysis and redistribution of tissue zinc in order to provide substrates for cells of the immune system and amino acids for synthesis of acute-phase proteins. When weanling rats were fed for 8 weeks on diets containing 100 $\mathrm{g} / \mathrm{kg}$ fat in the form of corn, fish, or coconut oils or butter (rich in oleic acid) before an intraperitoneal injection of recombinant human TNF $\alpha$, the increase in hepatic zinc concentration normally observed in the ensuing response did not occur in animals fed on the fish oil or butter diets (32) and the increase in plasma caeruloplasmin was smaller in the butter-fed animals than those fed on the 
Table 5 - Effect of dietary lipids on popliteal lymph node (PLN) weight following the graft versus host and host versus graft response in the rat.

This in vivo immune response was measured as described in the text. Statistical significance (oneway ANOVA) for $\mathrm{P}<0.05$ at least is indicated as follows: avs LF, $b_{v s} \mathrm{HCO},{ }^{c}$ vs OO, ${ }^{\mathrm{d}}$ vs SO, ${ }^{\mathrm{e}}$ vs EPO, fvs FO. LF, Low-fat; HCO, hydrogenated coconut oil; OO, olive oil; SO, safflower oil; EPO, evening primrose oil; FO, fish oil. Data taken from Sanderson et al. (34), with permission of Academic Press, Inc.

\begin{tabular}{lrc}
\hline Diet & $\begin{array}{c}\text { Graft vs Host } \\
\text { PLN weight }(\mathrm{mg})\end{array}$ & $\begin{array}{c}\text { Host vs Graft } \\
\text { PLN weight }(\mathrm{mg})\end{array}$ \\
\hline LF & $102.7 \pm 8.2^{\mathrm{cf}}$ & $27.5 \pm 1.5^{f}$ \\
HCO & $101.8 \pm 14.9^{f}$ & $28.6 \pm 2.0^{f}$ \\
OO & $77.3 \pm 7.5^{\mathrm{ae}}$ & $31.3 \pm 2.4^{f}$ \\
SO & $92.3 \pm 6.3^{f}$ & $30.8 \pm 2.0^{f}$ \\
EPO & $107.4 \pm 6.3^{\mathrm{cf}}$ & $32.5 \pm 1.8^{f}$ \\
FO & $67.8 \pm 5.7^{\mathrm{abde}}$ & $22.0 \pm 1.8^{\mathrm{abcde}}$
\end{tabular}

other diets (32). There was also no increase in the rate of protein synthesis in response to TNF $\alpha$ in the livers of animals fed the butter diet, whereas animals fed on the corn oil and coconut oil diets demonstrated the normal increase in protein synthesis associated with the acute-phase response (32). In a subsequent study, it was demonstrated that diets containing 50 or $100 \mathrm{~g} / \mathrm{kg}$ butter or olive oil completely suppressed the increases in tissue zinc content, liver protein synthesis and serum caeruloplasmin levels in response to subcutaneous Escherichia coli endotoxin, when compared with a maize oil diet or standard laboratory chow (33). In both studies, the butter and olive oil diets decreased the intensity of anorexia induced by TNF $\alpha$ or endotoxin (33), demonstrating clearly the diminished susceptibility to the lethal effects of both agents in experimental animals.

An alternative experimental model for in vivo immune responses is the 'graft versus host' (Gv.H) response, which can be elicited in rodents by injection of allogenic cells into the footpad of a host. The response primarily involves the polyclonal activation and proliferation of host B cells. The 'host versus graft' (Hv.G) response, on the other hand, is a $\mathrm{T}$ cell-mediated response, in which cytotoxic $\mathrm{T}$ lymphocytes of the host recognise MHC antigens on the injected cells. In both cases the enlargement of the popliteal lymph nodes (more than 15-fold in the Gv.H response and 4-fold in the Hv.G response) is due largely to proliferation of activated host cells within the lymph node, although there is also recruitment of cells from the bloodstream. Using this assay, Sanderson et al. (34) demonstrated that feeding rats a diet containing $200 \mathrm{~g} / \mathrm{kg}$ fish oil suppressed the Gv.H response compared with feeding a lowfat diet or diets containing $200 \mathrm{~g} / \mathrm{kg}$ coconut oil, safflower oil or evening primrose oil; feeding a diet containing $200 \mathrm{~g} / \mathrm{kg}$ olive oil had a similar effect, although the response was depressed only compared with the lowfat and evening primrose oil diets (34; Table $5)$. The expression of the adhesion molecules LFA-1 and ICAM-1 on lymphocytes from popliteal lymph nodes following a Gv.H response was significantly lower in animals fed the olive oil or fish oil diet compared with those fed the low-fat or coconut oil diet (34). It was speculated that the smaller popliteal lymph node size in animals fed the fish oil or olive oil diet may result from a suppression of both the activation of cells within the node and of the movement of cells from the bloodstream into the nodes (34). Interestingly, while the fish oil diet had a similar suppressive effect on the Hv.G response as that on the Gv.H response, the olive oil diet had no effect on the Hv.G response (33; Table 5); it appears, therefore, that in this model, olive oil is able to modulate in vivo responses involving B cells, but not those involving cytotoxic Tlymphocytes.

Although there are no published human studies which have set out to examine the effects of olive oil on in vivo immune responses, at least one study investigating the effects of fish oil supplements on immunological parameters (including the systemic humoral response to tetanus toxoid) in healthy 
volunteers has used olive oil as a placebo treatment (5). The authors claim to demonstrate an immunosuppressive effect of fish oil compared with olive oil, but the protocol is far from satisfactory. Six volunteers were involved in the study, only two of whom received the olive oil treatment and if the data are scrutinised, it is clear that a larger number of subjects may have produced different results (5), particularly since measurements of human immune responses are prone to substantial inter-individual variation.

\section{Olive oil and autoimmune disorders}

A much-cited study by Linos et al. (10) has suggested that there may be beneficial effects of olive oil consumption on rheumatoid arthritis (RA). This study compared the relative risk of development of RA in relation to lifelong consumption of olive oil in a Greek population and demonstrated that high consumers of olive oil (almost every day throughout life) were 4 times less likely to develop RA than those who consumed olive oil less than 6 times per month on average throughout their lives (10). Interestingly, the effect of fish consumption on relative risk for RA was also tested, but the effect was not statistically significant (10). The study, although of great interest, has the drawback that the population studied consisted of a very large proportion of high consumers of olive oil. However, there is further evidence that olive oil may have beneficial effects relating to RA. In a study by Kremer et al. (9) examining the effects of fish oil supplementation on the severity and progression of RA, olive oil was used as a placebo treatment, but clinical evaluations and immunologic tests showed it to have effects which were similar to those of fish oil. A total of 5 out of 45 clinical measures were significantly changed from baseline in the olive oil group, 8 out of 45 in a low-dose fish oil group and 21 out of 45 in a high-dose fish oil group (9). Production of interleukin-1 by macrophages was decreased in the olive oil group, although not to the same extent as either of the fish oil groups (9). The authors concluded that " $d i$ etary supplementation with olive oil is also associated with certain changes in immune function, which require further investigation."

\section{Conclusion}

Animal studies, depending on the protocol, species and type of measurement, generally support the idea that olive oil is capable of modulating functions of cells of the immune system. The effects appear to be similar to, albeit weaker than, those seen following feeding of diets containing fish oils. There is some evidence that the effects of olive oil on immune function in animal studies are due to oleic acid rather than to trace elements or antioxidants. Importantly, several studies have demonstrated effects of oleic acid-containing diets on in vivo immune responses.

In contrast, consumption of a MUFArich diet by humans does not appear to bring about a general suppression of immune cell functions. The effects of this type of diet in humans are limited to decreasing the expression of adhesion molecules on PBMNC (20) and decreasing LDL-induced adhesion of monocytes to endothelial cells (31), although there are trends towards decreases in NK cell activity and proliferation (20). The lack of a clear effect of MUFA in humans may be attributable to the higher level of monounsaturated fat used in the animal studies, as discussed previously; however, it is ultimately of importance to examine the effects of intakes which are in no way extreme. The intakes employed in the two human studies discussed closely correspond to current Mediterranean intakes and can readily be achieved through consumption of meals which use olive oil as the primary cooking fat.

Since the human studies concentrated on changes in macronutrient intake, the possibility that levels of trace elements or antioxi- 
dants varied between the diets and/or subjects cannot be excluded. Therefore, the suggestion that the effects observed in these studies are due to specific modulation of dietary oleic acid is favourable (given the changes in fatty acid composition in both), but not conclusive. Similarly, it is extremely difficult to determine conclusively whether the effects observed are indeed due to an increased level of MUFA or to a decreased level of SFA. The effects of MUFA on adhesion molecules are potentially important, since they appear to have a role in the pathology of a number of diseases involving the immune system. This area clearly deserves further exploration.

\section{References}

1. Nestle M (1995). Mediterranean diets: historical and research overview. American Journal of Clinical Nutrition, 61 (Suppl): 1313S-1320S.

2. Keys A (1970). Coronary heart disease in seven countries. Circulation, 41: 1-211.

3. Mensink RP \& Katan MB (1987). Effect of monounsaturated fatty acids versus complex carbohydrates on high-density lipoproteins in healthy men and women. Lancet, i: 122-124.

4. Mata $P$, Alvarez-Silva LA, Rubio MJ, Nuno $J$ \& De Oya M (1992). Effects of long-term monounsaturated $v s$ polyunsaturated-enriched diets on lipoproteins in healthy men and women. American Journal of Clinical Nutrition, 55: 846-850.

5. Virella G, Fourspring K, Hyman B, HaskillStroud R, Long L, Virella I, La Via M, Gross AJ \& Lopes-Virella M (1991). Immunosuppressive effects of fish oil in normal human volunteers: correlation with the in vitro effects of eicosapentaenoic acid on human lymphocytes. Clinical Immunology and Immunopathology, 61: 161-176.

6. Cleland LG, French JK, Betts WH, Murphy GA \& Elliot MJ (1988). Clinical and biochemical effects of dietary fish oil supplements in rheumatoid arthritis. Journal of Rheumatology, 15: 1471-1475.

7. Dehmer GJ, Popma JJ, van den Berg EK, Eichhorn EJ, Prewitt JB, Campbell WB, Jennings L, Willerson JT \& Schmitz JM (1988). Reduction in the rate of early restenosis after coronary angioplasty by a diet supplemented with $\mathrm{n}-3$ fatty acids. New England Journal of Medicine, 319: 733-740.

8. Milner MR (1989). Fish oil for preventing coronary restenosis. Lancet, II: 693.

9. Kremer JM, Lawrence DA, Jubiz W, DiGiacomo R, Rynes R, Bartholomew LE \& Sherman M (1990). Dietary fish oil and olive oil supplementation in patients with rheumatoid arthritis. Arthritis and Rheumatism, 33: 810-820.

10. Linos A, Kaklamanis E, Kontomerkos A, Koumantaki Y, Gazi S, Vaiopoulos G,
Tsokos GC \& Kaklamanis PH (1991). The effect of olive oil and fish consumption on rheumatoid arthritis - a case control study. Scandinavian Journal of Rheumatology, 20: 419-426.

11. Yaqoob P \& Calder PC (1993). The effects of fatty acids on lymphocyte functions. International Journal of Biochemistry, 25: 1705-1714.

12. Gurr MI (1983). The role of lipids in the regulation of the immune system. Progress in Lipid Research, 22: 257-287.

13. Yaqoob $P$, Newsholme EA \& Calder PC (1994). The effect of dietary lipid manipulation on rat lymphocyte subsets and proliferation. Immunology, 82: 603-610.

14. Yaqoob $P$, Newsholme EA \& Calder PC (1995). The effect of fatty acids on leukocytes subsets and proliferation in whole blood. Nutrition Research, 15: 279-287.

15. Yaqoob $P$, Newsholme EA \& Calder PC (1995). Influence of cell culture conditions on diet-induced changes in lymphocyte fatty acid composition. Biochimica et Biophysica Acta, 1255: 333-340.

16. Berger A, German JB, Chiang BL, Ansari $A A$, Keen CL, Fletcher MP \& Gershwin MR (1993). Influence of feeding unsaturated fats on growth and immune status of mice. Journal of Nutrition, 123: 225-233.

17. Gunstone FD, Harwood JL \& Padley FB (1994). The Lipid Handbook. 2nd edn. Chapman \& Hall, London, 79-82.

18. Jeffery NM, Yaqoob $P$, Newsholme EA \& Calder PC (1996). The effects of olive oil upon rat serum lipid levels and lymphocyte functions are due to oleic acid. Annals of Nutrition and Metabolism, 40: 7180.

19. Jeffery NM, Cortina M, Newsholme EA \& Calder PC (1997). Effects of variations in the proportions of saturated, monounsaturated and polyunsaturated fatty acids in the rat diet on spleen lymphocyte functions. British Journal of Nutrition, 77: 805823.

20. Yaqoob P, Knapper JA, Webb DH, Williams CM, Newsholme EA \& Calder PC
(1998). The effect of olive oil consumption on immune functions in middle-aged men. American Journal of Clinical Nutrition (in press).

21. Ferro-Luzzi A \& Branca F (1995). The Mediterranean diet, Italian style: prototype of a healthy diet. American Journal of Clinical Nutrition, 61 (Suppl): 1338S1345 S.

22. Herberman RB (1988). Lymphocytes: Cytotoxic activities. In: Gallin JI, Goldstein IM \& Snyderman R (Editors), Inflammation: Basic Principles and Clinical Correlates. Raven Press, New York, 613-630.

23. Yaqoob $P$, Newsholme EA \& Calder PC (1994). Inhibition of natural killer cell activity by dietary lipids. Immunology Letters, 41: 241-247.

24. Munro JM (1993). Endothelial-leukocyte adhesive interactions in inflammatory diseases. European Heart Journal, 14 (Suppl K): 72-77.

25. De Caterina R, Cybulsky MI, Clinton SK, Gimbrone Jr MA \& Libby P (1994). The omega-3 fatty acid docosahexaenoate reduces cytokine-induced expression of proatherogenic and proinflammatory proteins in human endothelial cells. Arteriosclerosis and Thrombosis, 14: 1829-1836.

26. Sanderson $P$, Yaqoob $P$ \& Calder $P C$ (1995). Effects of dietary lipid manipulation upon rat spleen lymphocyte functions and the expression of lymphocyte surface molecules. Journal of Nutritional and Environmental Medicine, 5: 119-132.

27. Chapman PT \& Haskard DO (1995). Leukocyte adhesion molecules. British Medical Bulletin, 51: 296-311.

28. Languino LR, Duperray A, Joganic KJ, Fornaro M, Thornton GB \& Altieri DC (1995). Regulation of leukocyte-endothelium interaction and leukocyte transendothelial migration by intercellular adhesion molecule 1-fibrinogen recognition. Proceedings of the National Academy of Sciences, USA, 92: 1505-1509.

29. Cronstein BN (1994). Adhesion molecules in the pathogenesis of rheumatoid arthri- 
tis. Current Opinion in Rheumatology, 6: 300-304.

30. Poston RN, Haskard DO, Coucher JR, Gall NP \& Johnson-Tidy RR (1992). Expression of intercellular adhesion molecule-1 in atherosclerotic plaques. American Journal of Pathology, 140: 665-673.

31. Mata P, Alonso R, Lopez-Farre A, Ordovas JM, Lahoz C, Garces C, Caramelo C, Codoceo R, Blazquez $E$ \& de Oya $M$
(1996). Effect of dietary fat saturation on LDL oxidation and monocyte adhesion to human endothelial cells in vitro. Arteriosclerosis, Thrombosis, and Vascular Biology, 16: 1347-1355.

32. Mulrooney HM \& Grimble RF (1993). Influence of butter and of corn, coconut and fish oils on the effects of recombinant human tumour necrosis factor- $\alpha$ in rats. Clinical Science, 84: 105-112.
33. Besler HT \& Grimble RF (1995). Comparison of the modulatory influence of maize and olive oils and butter on metabolic responses to endotoxin in rats. Clinical Science, 88: 59-66.

34. Sanderson $P$, Yaqoob $P$ \& Calder $P C$ (1995). Effects of dietary lipid manipulation upon graft vs host and host vs graft responses in the rat. Cellular Immunology, 164: 240-247. 